\title{
Levodopa peripheral pharmacokinetics and duration of motor response in Parkinson's disease
}

\author{
P A KEMPSTER, * J P FRANKEL, ${ }^{*}$ M BOVINGDON, $\uparrow$ R WEBSTER, $\dagger$ A J LEES, \\ G M STERN* \\ From the Department of Clinical Neurology, The Middlesex and University College Hospitals, Faculty of \\ Clinical Sciences* and Department of Pharmacology, $\dagger$ University College, London, UK
}

SUMMARY To assess the relative influence of central pharmacodynamic and peripheral pharmacokinetic factors on the duration of motor response to levodopa, the relationship between motor function and plasma levodopa levels was studied in 31 Parkinsonian patients. Duration of benefit from single levodopa doses while fasting depended on the degree to which the plasma levodopa level had declined over four hours; wearing off occurred when the plasma levodopa level had fallen to approximately $50 \%$ of peak concentration, irrespective of the duration of the motor response. Whilst the amplitude of motor response to levodopa is likely to be modified by alternations in dopamine receptor stimulation and sensitivity as the disease progresses, it is proposed that the duration of response is primarily determined by levodopa peripheral pharmacokinetics rather than by central pharmacodynamic factors associated with dopamine storage capacity.

Motor fluctuations eventually develop in most patients with Parkinson's disease who have received sustained levodopa treatment. ${ }^{12}$ It has been suggested that the evolution of motor oscillations occurs as a result of progressive reduction in duration of response to levodopa doses. ${ }^{3}$ Previous studies have shown that the peripheral pharmacokinetic handling of levodopa is similar in patients with long and short duration of levodopa therapy, ${ }^{4}$ so it seems unlikely that changes in levodopa peripheral pharmacokinetics in individual patients could account for the development of fluctuations. Cerebral pharmacodynamic factors have therefore been considered to determine the duration of response to levodopa. One postulated mechanism is that the duration of the motor response (MR) to a dose of levodopa depends on the capacity of surviving nigro-striatal terminals to store dopamine after it has been synthesised from exogenous levodopa; $;^{5}$ thus progressive reduction in dopamine storage capacity that accompanies the degeneration of the dopaminergic nigro-striatal pathway is held to be responsible for declining duration of effectiveness of levodopa doses.

Wearing off of dose responses has been shown to

Address for reprint requests: Dr A J Lees, Institute of Neurology, The National Hospital for Nervous Diseases, Queen Square, London WCIN 3BG, UK.

Received 1 December 1988.

Accepted 20 January 1989 occur when the plasma levodopa level is declining. ${ }^{6}$ If changing striatal levodopa pharmacodynamics are responsible for decreasing the duration of response ix individual patients, then the relationship between plasma levodopa levels and motor function should be different in patients with different durations of MR: One might expect to find that a relatively mild decline in plasma levodopa leads to wearing off in patients with advanced disease and short duration of response, whereas motor function is maintained over a much greater fall in blood level in patients with a longer duration of response (fig 1).

We have evaluated the relative influence of levodopa peripheral pharmacokinetic and central pharmacodynamic factors on the duration of response to oral levodopa by examining the relationship between plasma levels and MR time in patients with various MR durations.

\section{Patients}

Thirty one patients (18 male, 13 female) with idiopathic Parkinson's disease were studied. Their mean age was $59 \cdot 1$ years (39-73) and mean duration of disease $11 \cdot 1$ years (1-23). Motor disability ranged from minimal functional disability associated with stable control of motor symptoms to incapacitating motor oscillations. All were taking levodopa and mean duration of therapy was $9 \cdot 0$ years $(0.5-17)$. Apart from attempting to study roughly equal numbers of patients on short, medium and long-term levodopa therapy, subjects 


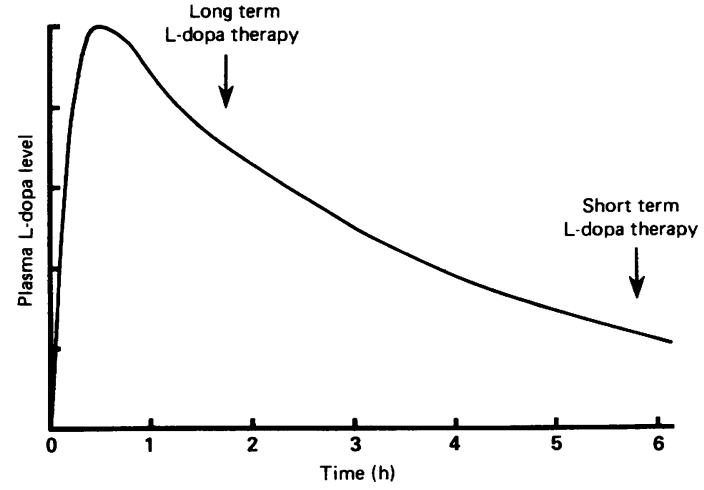

Fig 1 Stylised profile of plasma levodopa level following oral dosing in a single patient. According to the dopamine storage hypothesis, shortening of the duration of $M R$ occurs in individual patients as the disease progresses even though peripheral levodopa pharmacokinetics do not change. Thus after long term therapy, the effect of a single dose should wear off more quickly and at a higher plasma level (arrowed) than had occurred soon after commencing treatment.

were otherwise unselected for severity of disease or pattern of responsiveness to medication. Ten patients had been on levodopa for up to 5 years (six described stable motor function, two had symptoms of moderate motor fluctuations and two complained of severe oscillations), eight for between six and 10 years (one stable, four moderate and three severe), and 13 for greater than 10 years $(0$ stable, four moderate and nine severe). Clinical features of all patients are shown in table 1.

The studies were approved by the Ethical Committee of University College, London and all patients gave their informed consent.

\section{Methods}

Patients were studied early in the morning after all medication had been withheld for at least 10 hours. A single oral dose of levodopa $250 \mathrm{mg} /$ carbidopa $25 \mathrm{mg}$ was administered and patients remained fasting while blood was sampled at regular intervals over 6 hours and immediately centrifuged and stored at $-70^{\circ} \mathrm{C}$ until assayed.

\section{Motor assessments}

Serial motor assessments were performed at 15 minute intervals until wearing off occurred, as judged by comparison with the pre-dose baseline motor function. These measurements consisted of:

(1) unilateral hand tapping counts over 30 second intervals using two digital counters mounted $20 \mathrm{~cm}$ apart

(2) time taken for patients to rise from an armless chair, walk a six metre distance and return to the chair

Table 1 Summary of clinical characteristics and levodopa MR measurements. Severity of motor fluctuations: stable motor function $(S)$, moderate motor fluctuations $(+)$, severe oscillations $(++)$. Usual anti-Parkinsonian medications: levodopal carbidopa (S), levodopa/benserazide (M), bromocriptine (B), L-deprenyl (D), anticholinergic agents (A), amantidine (Am), subcutaneous apomorphine (Apo). ND—not determined.

\begin{tabular}{|c|c|c|c|c|c|c|c|c|}
\hline $\begin{array}{l}\text { Case } \\
\text { no }\end{array}$ & $\begin{array}{l}\text { Age } \\
\& \\
\text { sex }\end{array}$ & $\begin{array}{l}\text { Duration } \\
\text { of } \\
\text { disease } \\
(y r)\end{array}$ & $\begin{array}{l}\text { Duration } \\
\text { levodopa } \\
\text { therapy } \\
(y r)\end{array}$ & $\begin{array}{l}\text { Motor } \\
\text { fluctuations }\end{array}$ & $\begin{array}{l}\text { Usual } \\
\text { drugs }\end{array}$ & $\begin{array}{l}\text { Mo } \\
W e \\
\text { scor } \\
\text { off }\end{array}$ & on & $\begin{array}{l}\text { Time to } \\
\text { Wearing } \\
\text { off of } M R \\
\text { (h) }\end{array}$ \\
\hline $\begin{array}{r}1 \\
2 \\
3 \\
4 \\
5 \\
6 \\
7 \\
8 \\
9 \\
10 \\
11 \\
12 \\
13 \\
14 \\
15 \\
16 \\
17 \\
18 \\
19 \\
20 \\
21 \\
22 \\
23 \\
24 \\
25 \\
26 \\
27 \\
28 \\
29 \\
30 \\
31\end{array}$ & $\begin{array}{l}39 \mathrm{~F} \\
70 \mathrm{~F} \\
56 \mathrm{M} \\
39 \mathrm{~F} \\
63 \mathrm{~F} \\
54 \mathrm{M} \\
61 \mathrm{M} \\
67 \mathrm{M} \\
39 \mathrm{~F} \\
67 \mathrm{~F} \\
55 \mathrm{M} \\
53 \mathrm{M} \\
53 \mathrm{M} \\
65 \mathrm{~F} \\
43 \mathrm{M} \\
73 \mathrm{M} \\
70 \mathrm{M} \\
62 \mathrm{~F} \\
54 \mathrm{~F} \\
63 \mathrm{~F} \\
65 \mathrm{~F} \\
69 \mathrm{M} \\
56 \mathrm{M} \\
59 \mathrm{M} \\
57 \mathrm{M} \\
72 \mathrm{M} \\
73 \mathrm{~F} \\
59 \mathrm{M} \\
69 \mathrm{M} \\
47 \mathrm{M} \\
61 \mathrm{~F}\end{array}$ & $\begin{array}{r}13 \\
6 \\
4 \\
4 \\
10 \\
23 \\
9 \\
3 \\
18 \\
8 \\
10 \\
10 \\
6 \\
16 \\
5 \\
12 \\
5 \\
17 \\
14 \\
15 \\
13 \\
17 \\
5 \\
17 \\
6 \\
16 \\
8 \\
15 \\
15 \\
1 \\
23\end{array}$ & $\begin{array}{r}11 \\
4 \\
3 \\
2 \\
10 \\
12 \\
7 \\
3 \\
11 \\
7 \\
10 \\
10 \\
5 \\
11 \\
5 \\
10 \\
5 \\
17 \\
14 \\
10 \\
11 \\
12 \\
5 \\
17 \\
4 \\
12 \\
8 \\
15 \\
13 \\
0 \cdot 5 \\
13\end{array}$ & $\begin{array}{c}++ \\
+ \\
S \\
++ \\
++ \\
++ \\
+ \\
S \\
+ \\
++ \\
+ \\
++ \\
S \\
++ \\
++ \\
++ \\
S \\
++ \\
+ \\
++ \\
+ \\
++ \\
+ \\
+ \\
+ \\
+ \\
+ \\
+ \\
+ \\
+\end{array}$ & $\begin{array}{l}\text { M,Apo } \\
\text { M,B,D } \\
\text { M,D } \\
\text { S,B } \\
\text { S,D,A } \\
\text { S,A } \\
\text { S,D } \\
\text { S } \\
\text { M,D,A } \\
\text { S,D,A } \\
\text { S,D } \\
\text { S,B } \\
\text { M,B,D,A } \\
\text { S,D,A } \\
\text { S } \\
\text { S,D } \\
\text { S,D } \\
\text { M,B,Am } \\
\text { M,B,D } \\
\text { M,D } \\
\text { M,D,Am } \\
\text { S,D } \\
\text { S } \\
\text { M,B,D } \\
\text { M } \\
\text { S,D } \\
\text { S } \\
\text { S,D } \\
\text { S,A } \\
\text { S } \\
\text { M }\end{array}$ & $\begin{array}{r}28 \\
19 \\
11 \\
18 \\
20 \\
22 \\
11 \\
4 \\
27 \\
25 \\
15 \\
25 \\
24 \\
27 \\
20 \\
21 \\
10 \\
32 \\
24 \\
23 \\
34 \\
25 \\
9 \\
16 \\
14 \\
19 \\
5 \\
18 \\
21 \\
7 \\
29\end{array}$ & $\begin{array}{r}5 \\
7 \\
8 \\
2 \\
3 \\
10 \\
2 \\
2 \\
17 \\
11 \\
6 \\
8 \\
21 \\
8 \\
5 \\
7 \\
8 \\
13 \\
5 \\
8 \\
29 \\
10 \\
3 \\
0 \\
11 \\
3 \\
1 \\
6 \\
18 \\
5 \\
9\end{array}$ & $\begin{array}{l}2 \cdot 75 \\
5 \cdot 5 \\
3 \cdot 75 \\
2 \cdot 75 \\
5 \cdot 5 \\
4 \cdot 5 \\
4 \cdot 25 \\
7 \\
5 \cdot 5 \\
3 \cdot 75 \\
5 \cdot 75 \\
4 \cdot 75 \\
\text { ND } \\
4 \cdot 5 \\
4 \cdot 25 \\
3 \cdot 5 \\
7 \\
4 \cdot 5 \\
4 \cdot 0 \\
4 \cdot 75 \\
4 \cdot 25 \\
5 \cdot 0 \\
6 \cdot 5 \\
3 \cdot 0 \\
5 \cdot 0 \\
6 \cdot 25 \\
5 \cdot 0 \\
2 \cdot 75 \\
3 \cdot 25 \\
\text { ND } \\
6 \cdot 0\end{array}$ \\
\hline
\end{tabular}


(3) quantitation of tremor and dyskinetic involuntary movements according to simple four point scales $(0-$ nil, 1-mild, 2-moderate, 3-severe, 4 -incapacitating).

In order further to quantify amplitude of MR, patients were scored in off phases and at the time of peak motor improvement using the Webster disability scale, ${ }^{7}$ modified by inclusion of standard assessments of standing balance and ability to rise from a chair. The modified Webster scale thus assessed 12 areas of motor function with a maximum disability score of 36 .

\section{Plasma levodopa level measurements}

Plasma samples $(500 \mu \mathrm{l})$ were treated with $60 \%$ perchloric acid $(20 \mu \mathrm{l})$ to precipitate protein, and $20 \mu \mathrm{l}$ samples of clear supernatant were analysed by HPLC. The apparatus consisted of an MSI 660 Autosampler $\left(\right.$ at $\left.+5^{\circ} \mathrm{C}\right)$ and a 420 pump (Kontron, UK) with an LCA-15 Electrochemical detector (EDT, UK) at $0.70 \mathrm{~V}$ oxidation potential, and a Shimadzu CRIB integrator. Isocratic elution was carried out at $1.0 \mathrm{ml} /$ min at $20^{\circ} \mathrm{C}$ on a $15 \mathrm{~cm} \mathrm{S50DS}-2$ column (HPLC Technology UK). The mobile phase contained citric acid $(12.60 \mathrm{~g} / \mathrm{l})$, sodium dihydrogen orthophosphate $(5.68 \mathrm{~g} / \mathrm{l})$, heptanesulfonic acid sodium $(0.202 \mathrm{~g} / \mathrm{l})$, disodium EDTA $(0 \cdot 100 \mathrm{~g} / \mathrm{l})$ and acetonitrile $(20 \mathrm{ml} / \mathrm{l})$ in deionised water, finally adjusted to $\mathrm{pH} 2.5$ with hydrochloric acid, and degassed on-line. Interassay variability for levodopa concentration was $7 \cdot 1 \%$.

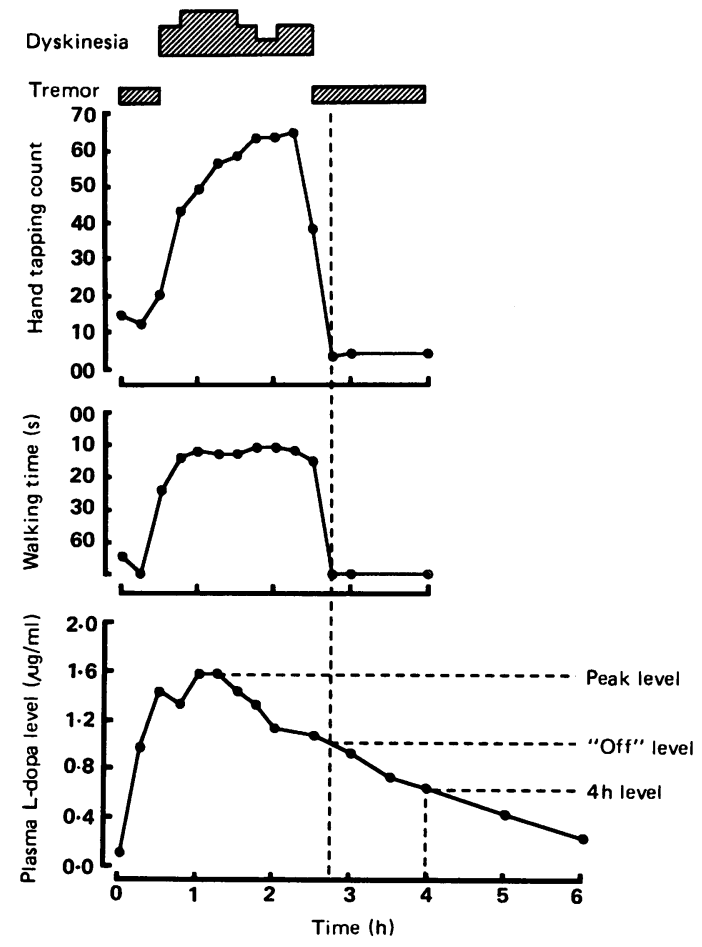

Fig 2 Serial hand tapping, walking time and plasma levodopa level measurements in Case I. Peak plasma levodopa level, level at time of wearing off ("off level") and level at four hours post-dose are shown.
Statistical analysis

Two tailed Student's $t$ test was used for comparison of grouped data. Linear regression and correlation analysis was applied to examine the relationship between plasma levodopa results and MR.

\section{Results}

Figure 2 shows a typical profile of motor assessments and serial plasma levodopa levels (Case 1). Wearing off occurred 2.75 hours after the levodopa/carbidopa dose and peak level, level at time of wearing off of motor response and level at 4 hours post-dose are indicated. The relationship between these values was used to evaluate the declining phase of the levodopa curve for each patient. By using the ratio of level at 4 hours to peak level and the ratio of level at time turning off to peak level, quantification of the fall in levodopa level from peak to these time points was obtained.

All patients were responsive to levodopa as judged by comparison of on and off phase modified Webster scoring. The pattern of motor response varied considerably among patients and was not always equally reflected by changes in measurements of handtapping, walking time and involuntary movements. Nevertheless, these motor assessments showed a detectable MR to levodopa in 29 out of the 31 patients. The time of wearing off of motor response was clearcut in all but two of the responders. These two (Cases 8 and 17), both with relatively mild motor disabilities and short duration of levodopa treatment, showed gradual decline in motor improvement that occurred approximately 7 hours after the levodopa dose.

The amplitude of MR, obtained by subtracting "on" from "off" phase modified Webster scores, was significantly greater in patients on longer term levodopa treatment. Mean MR amplitude for levo-

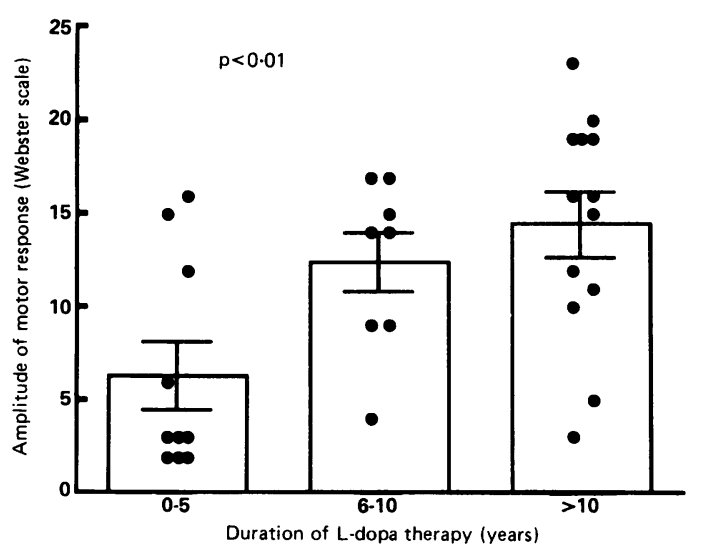

Fig 3 Amplitude of motor responses to levodopa in patients grouped according to number of years of levodopa therapy. 


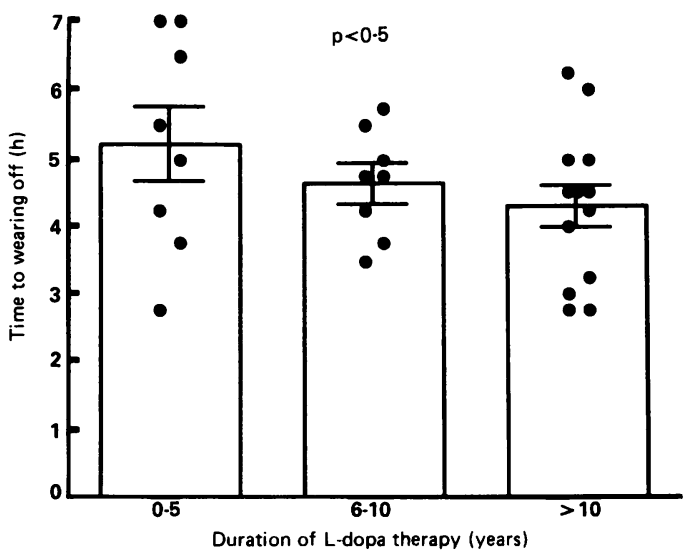

Fig 4 Time to wearing off of $M R$ in patients grouped according to number of years of levodopa therapy.

dopa treatment for up to 5 years was 6.4 compared with 14.5 for cases treated with levodopa for greater than 10 years $(\mathrm{p}<0.01)$ (fig 3). By contrast, time to wearing off of MR showed overlap among patients treated with levodopa for different periods and the small reduction in mean time in patients on levodopa for greater than 10 years compared with less than 5 years was not significant (fig 4).

MR duration was also analysed in relation to modified Webster score MR amplitude. Time to wearing off of MR was $5 \cdot 2$ hours for MR amplitude 0-8 (8 patients), $4 \cdot 2$ hours for amplitude $9 \cdot 16$ (14 patients) and 4.6 hours for amplitude $17-24$ (seven patients) $(0.5<0.1$ for difference between high and low MR amplitude groups).

Figure 5 illustrates the relationship between the ratio of levodopa level at four hours post-dose to peak levodopa level and the time to wearing off. There is a strong correlation between these two variables

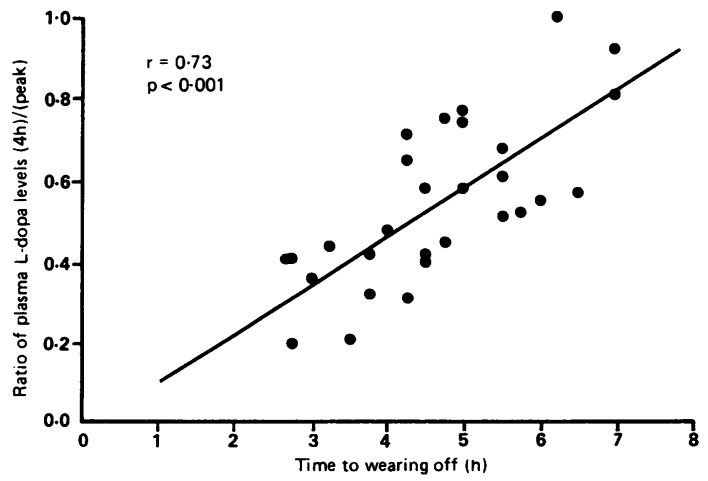

Fig 5 Ratio of plasma levodopa level at four hours post-dose to peak level plotted against time to wearing off of $M R$.

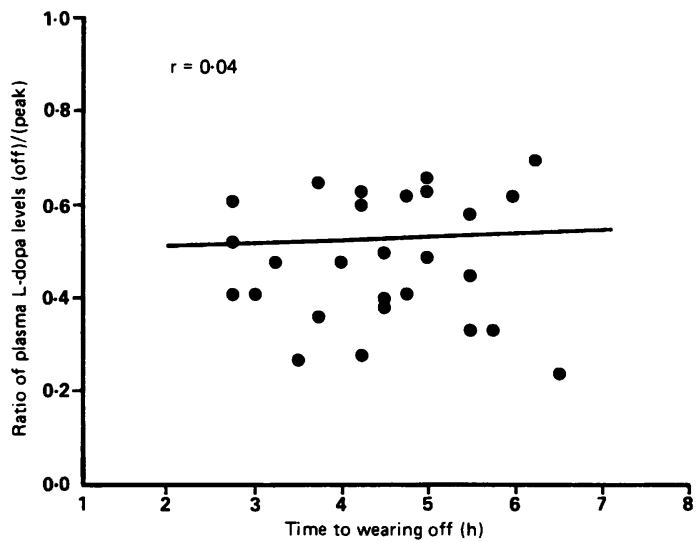

Fig 6 Ratio of plasma levodopa level at time of wearing off to peak level plotted against time to wearing off of motor response. (Plasma level at time of wearing off was not obtained in Cases 8 and 17.)

$(\mathrm{r}=0.73, \quad \mathrm{p}<0.01), \quad$ suggesting that plasma levodopa is more sustained four hours after dosing with respect to peak level in patients with more sustained MR. Individual correlation coefficients for the components of the levodopa level ratio were -0.41 for time to wearing off versus peak levodopa level, and +0.56 for time to wearing off versus levodopa level at four hours post-dose.

Figure 6 shows values for the ratio of levodopa level at the time of wearing off to peak level. No significant correlation was present between this ratio and the time to wearing off, suggesting that a similar degree of decline of levodopa level to approximately $50 \%$ of peak level resulted in wearing off of MR irrespective of time from dose to wearing off. Individual correlation coefficients were -0.42 for time to wearing off versus peak levodopa level and -0.23 for time to wearing off versus levodopa level at wearing off.

Comparison of pharmacokinetic parameters of peak levodopa level (Cmax), time to peak levodopa level (Tmax) and ratio of 4 hour to peak levels failed to show significant difference between patients taking levodopa for long and short periods (table 2).

Table 2 Mean pharmacokinetic parameters (standard deviation of mean) for patients with different durations of levodopa therapy. Differences in mean values for comparison of 0-5 years and greater than 10 years groups were not significant

\begin{tabular}{llll}
\hline $\begin{array}{l}\text { Duration of } \\
\text { levodopa } \\
\text { therapy }(y s)\end{array}$ & $\begin{array}{l}\text { Tmax } \\
(h)\end{array}$ & $\begin{array}{l}\text { Cmax } \\
\mu \mathrm{g} / \mathrm{ml}\end{array}$ & $\begin{array}{l}\text { Levodopa level } \\
\text { ratio } \\
{[\text { 4hrs]/[peak] }}\end{array}$ \\
\hline $0-5$ & $1.23(0.34)$ & $1.49(0.08)$ & $0.58(0.09)$ \\
$6-10$ & $1.25(0.25)$ & $1.35(0 \cdot 10)$ & $0.50(0.07)$ \\
$>10$ & $1.14(0.29)$ & $1.56(0.10)$ & $0.55(0.05)$ \\
\hline
\end{tabular}




\section{Discussion}

The concept that progressive reduction in the duration of MR to levodopa is important in the development of Parkinsian motor oscillations has been used to explain differences in clinical responses to long and short term levodopa therapy. Early in the disease course, patients appear to have a stable MR to serial levodopa doses and neither patient nor clinician are aware of motor fluctuations. With the passage of time, increasingly prominent periodic decline of motor function occurs and individual doses of levodopa produce benefit for a few hours only. The present study shows that MR to a single oral levodopa dose can be detected soon after commencing levodopa treatment in patients with apparently stable motor function, and that the duration of these motor responses in fact differs little from those found in patients with advanced disease and much greater amplitude of MR. These findings are in agreement with MR duration measurements following short term intravenous levodopa infusions which show that the time course of decline of motor function is similar in patients who have been treated with levodopa for long as well as for short periods. ${ }^{8}$

Comparison of pharmacokinetic parameters confirms previous observations that peripheral levodopa pharmacokinetics are similar irrespective of duration of disease or of levodopa therapy, and presumably remain unchanged in individual patients. The hypothesis that contracting MR time is a cause of oscillating motor function ${ }^{5}$ predicts that, following levodopa doses, progressively less decline in blood levodopa level will result in wearing off of motor response as oscillations become increasingly apparent. However, our results suggest that the degree of fall of blood levodopa level from peak level that leads to wearing off of MR appears to be similar irrespective of time from dose to wearing off. The time course of motor responses mirror the profile of blood levodopa levels and differences in duration of response are explained by differences in the degree of decline in blood levodopa level over 4 hours. This study has not explored the role of other factors which may influence motor oscillations such as protein intake and the effects of multiple doses. Nevertheless it did not provide evidence that central pharmacodynamic factors associated with striatal dopamine storage capacity cause less sustained MR for a given plasma levodopa level in patients with shorter duration of responses.

Evidence from positron emission neuroimaging suggest that administration of levodopa to Parkinsonian patients results in less prolonged striatal accumulation of dopamine compared with normal subjects. ${ }^{9}$ This probably reflects differences in accumulation of dopamine in intraneuronal vesicles of nigro-striatal terminals and has been taken as support for the hypothesis that striatal dopamine storage capacity is an important determinant of the duration of MR. However, the clinical effects of administered levodopa may not be dependent on vesicular storage and synaptic release of dopamine by surviving nigrostriatal neurons. Aromatic amino acid decarboxylase, the enzyme which converts levodopa to dopamine, is widely distributed in brain tissue and animal studies suggest that significant amounts of levodopa can be synthesised outside dopaminergic neurons. ${ }^{10}$ Release of dopamine by nigro-striatal neurons may also occur independently of vesicular storage and synaptic release, with dopamine diffusing out of striatal terminals after synthesis. " Our observations that MR time correlates with the peripheral levodopa level profile are consistent with the notion that exogenous levodopa does not rely on synaptic storage and release of dopamine by nigro-striatal terminals to produce its clinical effects. When factors such as competition for neutral amino acid transport across the blood-brain barrier are minimised, the level of extracellular dopamine in the vicinity of striatal dopamine receptor sites may vary in time with blood levodopa levels. Further clinical evidence that dopamine storage capacity is not of major importance in determining the time course of levodopa motor responses comes frone observations in patients with asymmetry of Parkin sonian motor deficits attributed to asymmetry of nigral cell degeneration. Despite presumed asymmetr 8 of dopamine storage capacity, no asymmetry in dura? tion of MR to levodopa doses occurs. ${ }^{12}$

The evolution of motor oscillations would be beste examined by longitudinal studies in individual patients over many years. Nevertheless it is proposed that levodopa peripheral pharmacokinetics and duration of MR remain unaltered as the disease progresses but that increasing amplitude of motor responses leads to clinically apparent fluctuations. Increasing off phase disability due to progressive nigro-striatal degeneration and changes in the central pharmacodynamics of dopamine receptor stimulation may both contribute to changes in response amplitude. However, the duration of levodopa MR is essentially determined by peripheral pharmacokinetic factors.

PAK and JPF were supported by the Kate Stillman Research Fellowship. We thank the Medical Illustration and Photographic Departments of The Middlesex Hospital for assistance with preparation of the figures.

\section{References}

1 Marsden CD, Parkes JD. Success and problems of long term levodopa therapy in Parkinson's disease. Lancet 1977;i:345-9.

2 Fahn S. "On-off" phenomenon with levodopa therapy in 
Parkinsonism. Neurology 1974;24:431-41.

3 Marsden CD, Parkes JD, Quinn N. Fluctuations of disability in Parkinson's disease: clinical aspects. In: Marsden CD, Fahn S, eds. Movement Disorders. London: Butterworths Scientific, 1982:96-122.

4 Gancher ST, Nutt JG, Woodward WR. Peripheral pharmacokinetics of levodopa in untreated, stable and fluctuating Parkinsonian patients. Neurology 1987; 37:940-4.

5 Marsden CD. "On-off" phenomenon in Parkinson's disease. In: Rinne UK, Klinger M, Stamm S, eds. Parkinson's Disease: Current Progress, Problems in Management. Amsterdam: Elsevier, 1980:241-54.

6 Shoulson I, Glaubiger GA, Chase TN. On-off response: clinical and biochemical correlations during oral and intravenous levodopa administration in Parkinsonian patients. Neurology 1975;25:1144-8.

7 Webster DD. Critical analysis of the disabilities in Parkinson's disease. Modern Treatment 1968;5:257-82.
8 Gancher ST, Nutt JG, Woodward W. Response to brief levodopa infusions in Parkinsonian patients with and without motor fluctuations. Neurology 1988;38:712-6.

9 Leenders KL, Palmer AJ, Quinn N, et al. Brain dopamine metabolism in patients with Parkinson's disease measured with positron emission tomography. J Neurol Neurosurg Psychiatry 1986;49:853-60.

10 Melamed E, Hefti F, Pettibone DJ, Liebman J, Wurtman RJ. Localisation of aromatic amino acid decarboxylase in the rat corpus striatum: implications for action of levodopa in Parkinsonism. Neurology 1981;31:651-5.

11 Melamed E. Mechanism of action of levodopa. In: Koller W, ed. Handbook of Parkinson's Disease. New York: Dekker, 1987:355-70.

12 Kempster PA, Gibb WRG, Lees AJ, Stern GM. Asymmetry of substantia nigra neuronal loss in Parkinson's disease and its relevance to the mechanism of motor fluctuations. J Neurol Neurosurg Psychiatry 1989;52: 72-76. 